\title{
The effect of vancomycin powder on human dural fibroblast culture and its implications for dural repair during spine surgery
}

\author{
Presented at the 2016 AANS/CNS Joint Section on Disorders of the Spine and Peripheral Nerves \\ Ezequiel Goldschmidt, MD, PhD, ${ }^{1-3}$ Jorge Rasmussen, MD, ${ }^{2,3}$ Joseph D. Chabot, DO, ${ }^{1}$ \\ Gurpreet Gandhoke, MD, ${ }^{1}$ Emilia Luzzi, MD, ${ }^{3}$ Lina Merlotti, MD, ${ }^{3}$ Romina Proni, MD, ${ }^{3}$ \\ Mónica Loresi, MD, ${ }^{3}$ D. Kojo Hamilton, MD, ${ }^{1}$ David O. Okonkwo, MD, PhD, ${ }^{1}$ Adam S. Kanter, MD, ${ }^{1}$ \\ and Peter C. Gerszten, MD, MPH ${ }^{1}$
}

'Department of Neurological Surgery, University of Pittsburgh School of Medicine, UPMC Health System, Pittsburgh, Pennsylvania; and ${ }^{2}$ Department of Neurological Surgery, and ${ }^{3}$ Institute of Basic Science and Experimental Medicine (ICBME), Hospital Italiano de Buenos Aires, Argentina

\begin{abstract}
OBJECTIVE Surgical site infections (SSIs) are a major source of morbidity after spinal surgery. Several recent studies have described the finding that applying vancomycin powder to the surgical bed may reduce the incidence of SSI. However, applying vancomycin in high concentrations has been shown in vitro to inhibit osteoblast proliferation and to induce cell death. Vancomycin may have a deleterious effect on dural healing after repair of an intentional or unintentional durotomy. This study was therefore undertaken to assess the effect of different concentrations of vancomycin on a human dura mater cell culture.
\end{abstract}

METHODS Human dura intended for disposal after decompressive craniectomy was harvested. Explant primary cultures and subcultures were subsequently performed. Cells were characterized through common staining and immunohistochemistry. A growth curve was performed to assess the effect of different concentrations of vancomycin (40, 400, and $4000 \mu \mathrm{g} / \mathrm{ml}$ ) on cell count. The effect of vancomycin on cellular shape, intercellular arrangement, and viability was also evaluated.

RESULTS All dural tissue samples successfully developed into fusiform cells, demonstrating pseudopod projections and spindle formation. The cells demonstrated vimentin positivity and also had typical features of fibroblasts. When applied to the cultures, the highest dose of vancomycin induced generalized cell death within 24 hours. The mean $( \pm$ SD) cell counts for control, 40, 400, and $4000 \mu \mathrm{g} / \mathrm{ml}$ were $38.72 \pm 15.93,36.28 \pm 22.87,19.48 \pm 6.53$, and 4.07 \pm 9.66 , respectively ( $p<0.0001$, ANOVA). Compared with controls, vancomycin-exposed cells histologically demonstrated a smaller cytoplasm and decreased pseudopodia formation resulting in the inhibition of normal spindle intercellular arrangement.

CONCLUSIONS When vancomycin powder is applied locally, dural cells are exposed to a concentration several times greater than when delivered systemically. In this in vitro model, vancomycin induced dural cell death, inhibited growth, and altered cellular morphology in a concentration-dependent fashion. Defining a safe vancomycin concentration that is both bactericidal and also does not inhibit normal dural healing is necessary.

http://thejns.org/doi/abs/10.3171/2016.3.SPINE151491

KEY WORDS CSF leakage; durotomy; spine surgery; surgical site infection; vancomycin

$\mathrm{S}$ URGICAL site infections (SSIs) can be a major complication leading to worse outcomes after spinal surgery. ${ }^{17}$ Postoperative infection can lead to repeat surgery for wound revision or removal of implanted hardware. The increasing incidence of surgical wounds infect- ed with resistant strains of bacteria constitutes a growing problem and makes proper long-term antibiotic management difficult. $3,5,13$

In addition to standard antiseptic surgical technique, perioperative measures including intraoperative intrave-

ABBREVIATIONS $\mathrm{Cl}=$ confidence interval; $\mathrm{LV}=$ lyophilized vancomycin; $P B S=$ phosphate-buffered saline; $\mathrm{SSI}=$ surgical site infection

SUBMITTED December 18, 2015. ACCEPTED March 21, 2016.

INCLUDE WHEN CITING Published online June 3, 2016; DOI: 10.3171/2016.3.SPINE151491. 
nous antibiotics, ${ }^{5,11}$ presurgical baths, ${ }^{2}$ and mupirocin nasal ointments ${ }^{10}$ have been effective in reducing the incidence of SSI after spinal surgery. The topical application of lyophilized vancomycin (LV) to the surgical bed following spinal surgery can achieve very high concentrations in the surgical site with minimal systemic repercussions. ${ }^{6,18,19} \mathrm{Al}-$ though 3 recently published meta-analyses have described a decrease in the incidence of SSI after spine surgery with the use of topical vancomycin powder applied before closure, ${ }^{1,12,21}$ the true benefit of this practice is still controversial. ${ }^{20}$

Eder at al. ${ }^{4}$ reported that $6 \mathrm{mg} / \mathrm{cm}^{2}$ of vancomycin applied to a human-derived primary culture of osteoblasts induces massive cellular death and that $3 \mathrm{mg} / \mathrm{cm}^{2}$ significantly inhibited cellular growth and migration capacity, two fundamental processes necessary to achieve healing. The effect of LV on the healing process of local tissues after surgery has not been extensively studied. Rathbone et al. ${ }^{16}$ found that $5000 \mu \mathrm{g} / \mathrm{ml}$ of vancomycin diminishes the number of osteoblasts present in a culture by $50 \%-74 \%$.

The effect of topical vancomycin on dural cellular growth is also poorly understood. After intentional or unintentional durotomy during spine surgery, proper dural repair and healing are essential to avoid CSF leakage, which is an independent risk factor for meningitis and worse surgical outcomes..$^{9,14,15}$ No study has addressed the direct effect of LV on normal dural healing. The purpose of the current investigation was to specifically assess the effect of LV at different concentrations on a human dural fibroblast culture. Such an effect may have important clinical implications in the setting of closures of both intentional and unintentional durotomy.

\section{Methods \\ Specimen Collection}

The protocol was approved by the ethics committee of the Hospital Italiano de Buenos Aires, in Buenos Aires, Argentina. Human dural specimens were harvested following decompressive craniectomies where dura was resected and intended for disposal. Informed consent was obtained in every case. Specimens were kept at $4^{\circ} \mathrm{C}$ in a sterile saline solution overnight and processed at the laboratory the following morning. Five different samples from 5 different patients were used. Each control sample was compared with a treated one from the same patient.

As previously described, ${ }^{7,8}$ specimens were divided into 2-mm fragments and cultured on $30-\mathrm{mm}$ culture plates (Nunc) with $2 \mathrm{ml}$ of Dulbecco modified Eagle medium supplemented with $100 \mathrm{U} / \mathrm{ml}$ penicillin, $100 \mu \mathrm{g} / \mathrm{ml}$ streptomycin, $0.25 \mu \mathrm{g} / \mathrm{ml}$ amphotericin B (Gibco), 200 $\mathrm{mM}$ alpha-glutamine (Gibco), and 10\% bovine fetal serum (Bioser). To obtain subcultures the tissue specimens were seeded, allowing the cells to migrate over the plate. When cell confluence was reached, the tissue specimens were removed from the plate, and the cells were subcultured for amplification. The plate was treated with a $0.25 \%$ trypsin solution (Sigma) for 3 minutes. After neutralizing the trypsin with a culture medium, cells were centrifuged at $1200 \mathrm{G}$ for 10 minutes, resuspended, and plated onto T-75 flasks (Nunc). Amplified cells were quantified as per the Trypan Blue exclusion method, and 10,000 cells were seeded on $30-\mathrm{mm}$ plates. All experiments for the study were performed with twice-subcultured cells.

\section{Immunohistochemistry}

Cells were typified by common histological techniques and immunohistochemistry. Cells were characterized by staining with antivimentin antibodies (Millipore). The culture was fixed in $4 \%$ paraformaldehyde for 24 hours and included in paraffin. Axial slices were performed, placed onto slides, and rehydrated in the usual fashion. They were then washed with phosphate-buffered saline (PBS) $\mathrm{pH}$ 7.2, treated with PBS with Triton X-100 for 10 minutes, and incubated with PowerblockTM (BioGenex) for 5 minutes to block nonspecific binding sites. The primary antibody was incubated overnight at $4^{\circ} \mathrm{C}$ in a moist chamber. The following day, they were washed with PBS and incubated with a biotinylated secondary antibody (MultilinkTM; BioGenex) for 30 minutes at room temperature, and then with fluorescein streptavidin (Vector Labs) for 60 minutes. They were washed a final time with PBS pH 8.2. Lastly, they were mounted and analyzed under a Nikon Eclipse E400 microscope. Nuclei were stained with Hoeschl stain.

\section{Treatment With Vancomycin}

Vancomycin (Pfizer) was used at 3 different concentrations, chosen to reflect the variability that may be found clinically in postsurgical tissue. Although the true concentration of LV in wounds is unknown, we chose these concentrations to address the spectrum that was found in human wounds by Sweet et al..$^{18}$ Cells were constantly exposed to $\mathrm{LV}$, and both the medium and the antibiotic were changed every 2 days. Each concentration was applied to 5 different plates $(n=5)$.

\section{Cell Count}

Cells were counted daily using a bright-field microscope (Nikon Eclipse E400). The cell count was expressed as the average of 10 fields at a magnification of 10 . A control curve and a curve for each concentration of LV were performed. Photographs were taken to simplify cell counting.

\section{Analysis of Cell Structure and Viability}

On the third day of culture, 9 treated plates were compared with control samples to assess for cell structural changes and viability. To assess for cell viability, a mixed solution containing acridine orange and ethidium bromide was added to 3 culture plates, and the cells were then observed under the florescence microscope. Because live cells are not permeable to ethidium bromide, and dead cells are permeable to both dyes, live cells appear green and dead cells appear red. The supernatant of the 3 treated cultures was analyzed with the Trypan Blue exclusion test to evaluate for unattached cells, a sign of lost viability. The hematoxylin and eosin technique was used to look for structural differences of the fibroblast cells (i.e., cell morphology) between 3 treated controls and the different samples exposed to $\mathrm{LV}$. 

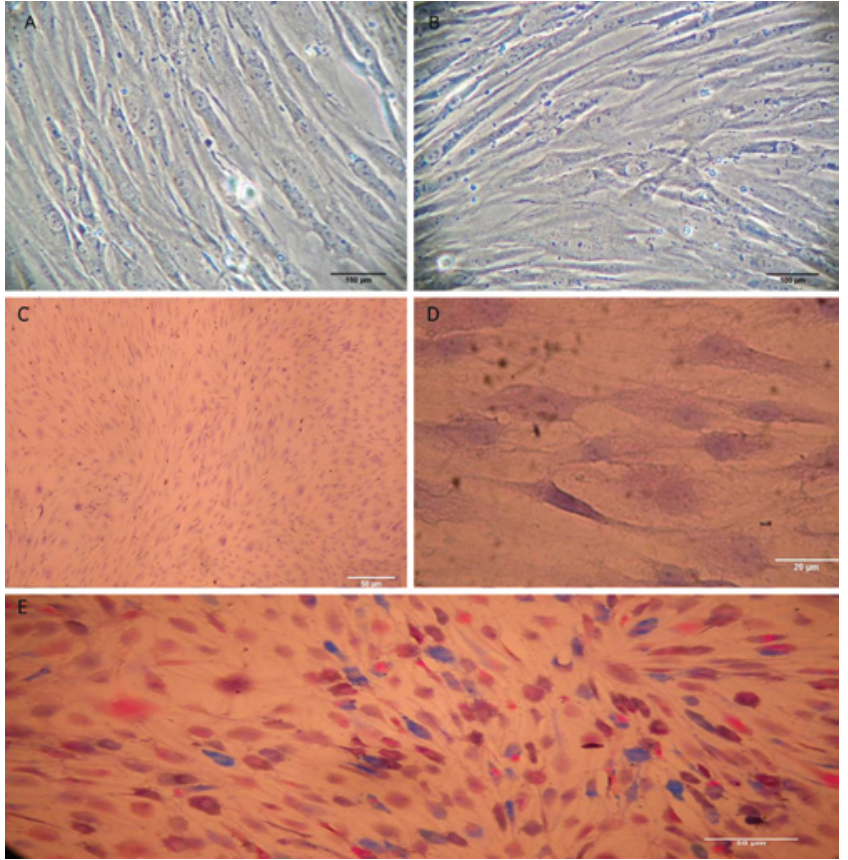

FIG. 1. Dural fibroblast cell characterization, explant culture. A and B: Appearance of cultured cells under the phase-contrast microscope. The cells exhibit an elongated, spindle-shaped cytoplasm, 1 nuclei with 2 nucleoli. A fusiform intercellular arrangement of the migrating cells is evident. Original magnification $\times 100$. C and D: Appearance of cells after $\mathrm{H}$ \& $\mathrm{E}$ staining. The cells exhibit a fibrillary cytoplasm, numerous interconnections, as well as the fusiform pattern previously described. Original magnification $\times 10(C), \times 100$ (D). E: The Masson trichrome technique exhibits similar findings along with the presence of scattered blue spots, indicative of collagen production. Original magnification $\times 40$.

\section{Statistical Analysis}

An ANOVA model for repeated measures was used. Cell count was taken as a response variable. Explanatory variables included treatment with LV at 3 different concentrations. The 6 measurements used were chronologically ordered along a 6-consecutive-day sequence. Main effects (i.e., effects of fixed factors) on the number of cells present in the culture were estimated. Differences between means were assessed with the Student t-test. Statistical analysis was performed using SPSS software (version 20, IBM). All $p$ values $<0.0125$ were considered statistically significant for ANOVA analysis (Bonferroni correction for multiple testing), and $<0.05$ for other comparisons.

\section{Results}

Dural samples were harvested from 5 patients during craniotomy. A cell subculture was successfully obtained from each case. All cultured cells had similar characteristics of the fibroblast dural cultures previously described by our group, including elongated elements displayed in a fusiform pattern and vimentin positivity (Figs. 1 and 2). The Masson trichrome stain revealed morphological features typical for fibroblasts as well as collagen deposition.

\section{Cell Count}

A growth curve was performed for all 5 subcultures.
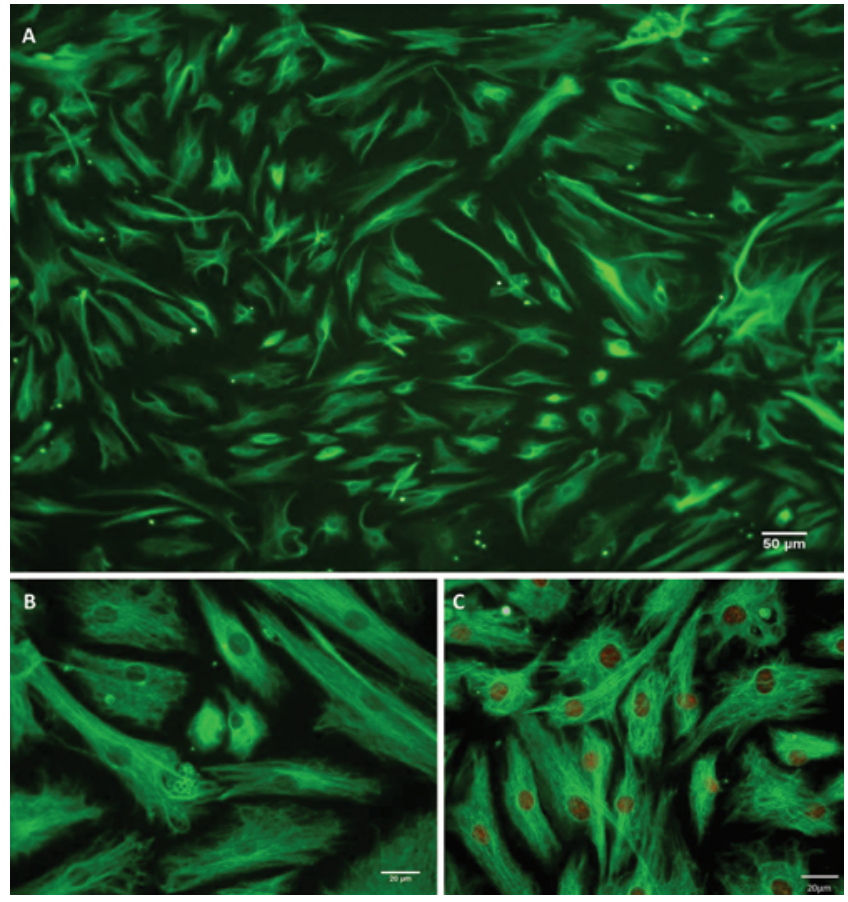

FIG. 2. Indirect immunofluorescence for vimentin. A and B: Cells are strongly positive for this marker that demonstrates intermediate filaments within the cytoplasm, typical for fibroblasts. Original magnification $\times 40(A), \times 100$ (B). C: Nuclei are stained with acridine orange indicating a homogeneous culture of fibroblasts. Original magnification $\times 100$.

The plates $(30 \mathrm{~mm})$ were seeded with 10,000 dural fibroblast cells. The next day (Day 0), cells attached to the plates were counted and divided among controls or 1 of the 3 different concentrations of LV $(n=5)$. There were no differences in the number of cells present in the samples destined to each treatment. In the $4000 \mu \mathrm{g} / \mathrm{ml}$ treatment group, each plate exhibited massive cell death demonstrated by the presence of unattached cells (Fig. 3) that were confirmed as nonviable by the Trypan Blue exclusion method.

Adding 40 and $400 \mu \mathrm{g} / \mathrm{ml}$ of LV induced a significant reduction in the number of cells present in the culture over the 5-day period (control, $38.72 \pm 15.93$ cells; $40 \mu \mathrm{g} / \mathrm{ml}$, $36.28 \pm 22.87$ cells; $400 \mu \mathrm{g} / \mathrm{ml}, 19.48 \pm 6.53$ cells; and $4000 \mu \mathrm{g} / \mathrm{ml}, 4.07 \pm 9.66 ; \mathrm{p}<0.0001$, ANOVA). Although the difference was significant between the control cultures and cells treated with $40 \mu \mathrm{g} / \mathrm{ml}$ during the first 3 days, this difference disappeared by Day 4 (Fig. 4).

\section{Structural Changes}

On the third day after seeding, cells were analyzed for structural changes. Because no cells were alive in the cultures treated with $4000 \mu \mathrm{g} / \mathrm{ml} \mathrm{LV}$, viability and structural changes were analyzed for the $400 \mu \mathrm{g} / \mathrm{ml}$ treatment group only. Cells exposed to the $400 \mu \mathrm{g} / \mathrm{ml} \mathrm{LV}$ concentration showed a marked reduction in pseudopodia formation and smaller cytoplasms (Fig. 5). Also, the normal fusiform arrangement pattern characteristic of an untreated fibroblast culture was replaced by a large number of abnormal round cells, indicating cytoplasm de-arrangement. Similar find- 


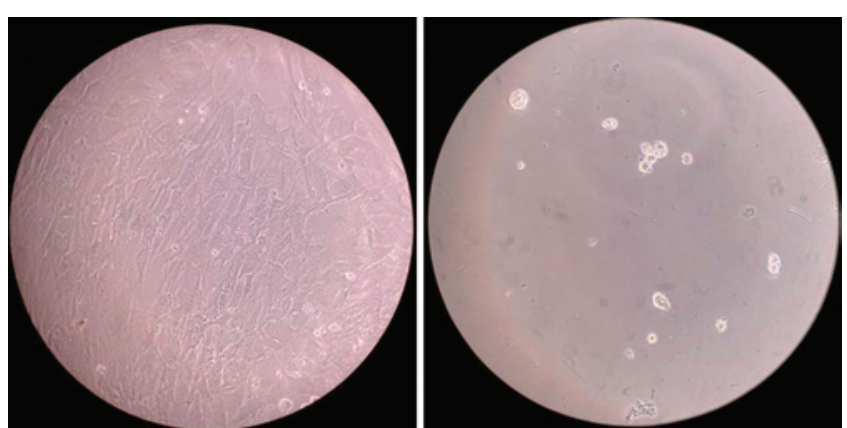

FIG. 3. Control fibroblasts (left) and fibroblasts treated with $4000 \mu \mathrm{g} / \mathrm{ml}$ of LV (right) examined with the inverted microscope. Control fibroblasts demonstrate normally shaped cells attached to the Petri dish. Twentyfour hours after treatment with LV $(4000 \mu \mathrm{g} / \mathrm{ml})$ the cells lose their capacity to remain attached to the Petri dish and are floating in the culture medium. Original magnification $\times 100$

ings were present in 3 samples both observed under the inverted microscope and after $\mathrm{H} \& \mathrm{E}$ staining.

\section{Cell Viability}

Fewer viable cells, measured by differential uptake of ethidium bromide and acridine orange, was noted in the $\mathrm{LV} 400 \mu \mathrm{g} / \mathrm{ml}$ group compared with controls $(\mathrm{n}=3)$. Also, a significant number of dead cells was observed on the supernatant of the treated specimens $(11,600 \pm 2886$ cells $)$, while all the cells in the control group remained attached to the plate in a normal and healthy fashion (Fig. 5).

\section{Discussion}

The use of vancomycin powder to prevent SSIs after spinal surgery is controversial. In a recent meta-analysis, Bakhsheshian et al. ${ }^{1}$ concluded that the topical application of this antibiotic had an overall protective effect against SSI (odds ratio $0.23,95 \%$ confidence interval [CI] $0.11-$ $0.5)$. However, the only randomized controlled trial included in their analysis did not show any benefit between the treatment and control groups. Furthermore, effective concentrations required to achieve the desired bactericidal effect are difficult to evaluate and have not been well established.

Although higher concentrations of LV may indeed improve its efficacy in SSI prevention, the effect of higher concentrations of this antibiotic on dural healing has never been evaluated. In the current study, LV applied in 3 different concentrations was demonstrated to induce cellular necrosis and inhibit proliferation of human dural fibroblasts. Healing after surgery involves an initial inflammatory response followed by a proliferative phase that requires viable fibroblasts to fill the defect and synthesize a new extracellular matrix. The presence of LV could therefore inhibit this process. ${ }^{20}$

Eder et al. ${ }^{4}$ described the effect of $3-12 \mathrm{mg} / \mathrm{cm}^{2}$ of LV on a primary human-derived osteoblast culture. Similar to the present study, their model also found that LV induced cell death in a concentration-dependent manner. However, the concentrations used by these investigators were generally many times larger than the ones used in our study. Eder et al. also observed changes in cell morphology that were similar to the ones described in the current study. Their experiments included only a single examination of cells 24 hours after application of antibiotics alone, but not a growth curve. Furthermore, in that study data were collected at a single time point (status-post 24 hours) and

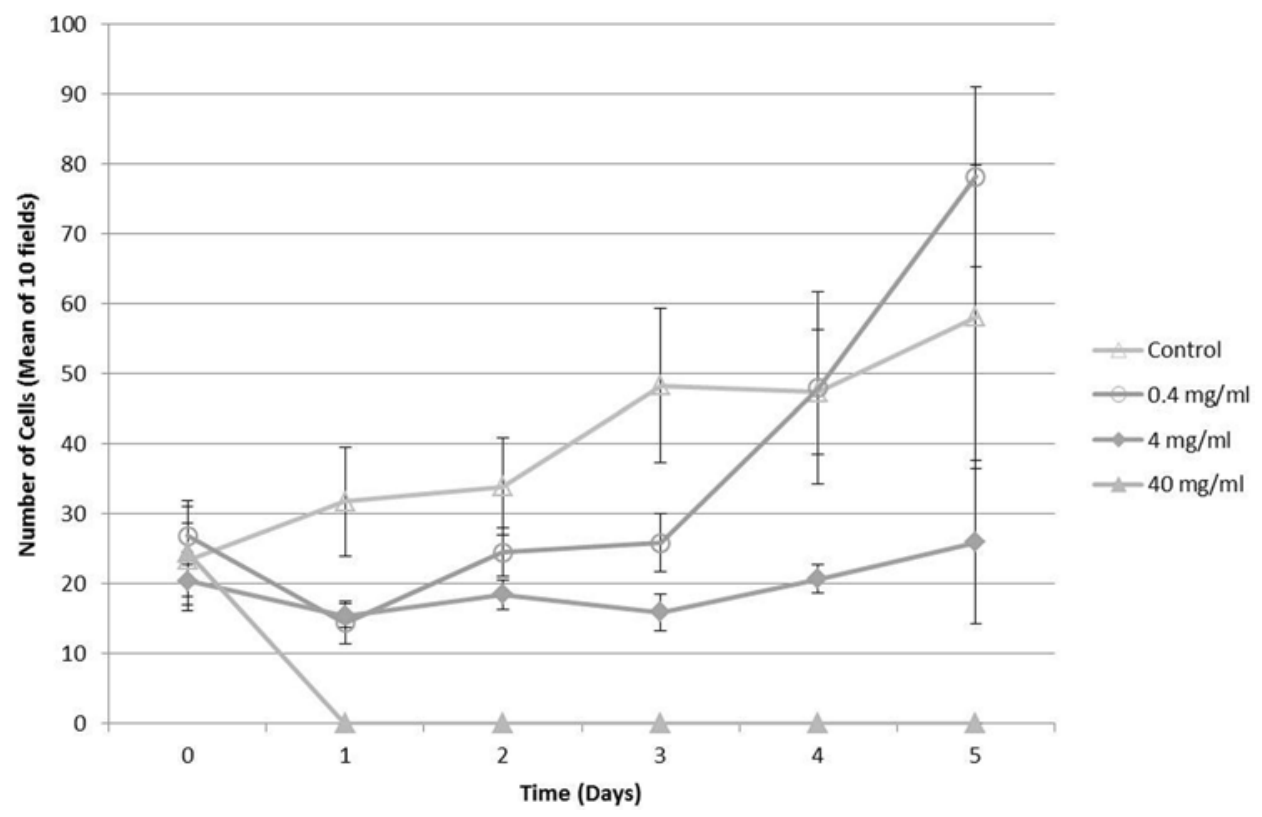

FIG. 4. Growth curve of control and plates exposed to increasing concentrations of LV. On Day 0 cells were counted and randomly assigned to 1 of 4 treatments. The highest LV concentration $(4000 \mu \mathrm{g} / \mathrm{ml}$, solid triangles) induced generalized cellular death. By the third day plates exposed to $40 \mu \mathrm{g} / \mathrm{ml}$ (open circles) and $400 \mu \mathrm{g} / \mathrm{ml}$ (diamonds) had significantly fewer cells than the control group (open triangles). This effect disappeared for the lowest concentration but not for the cells exposed to $400 \mu \mathrm{g} / \mathrm{ml}$. 

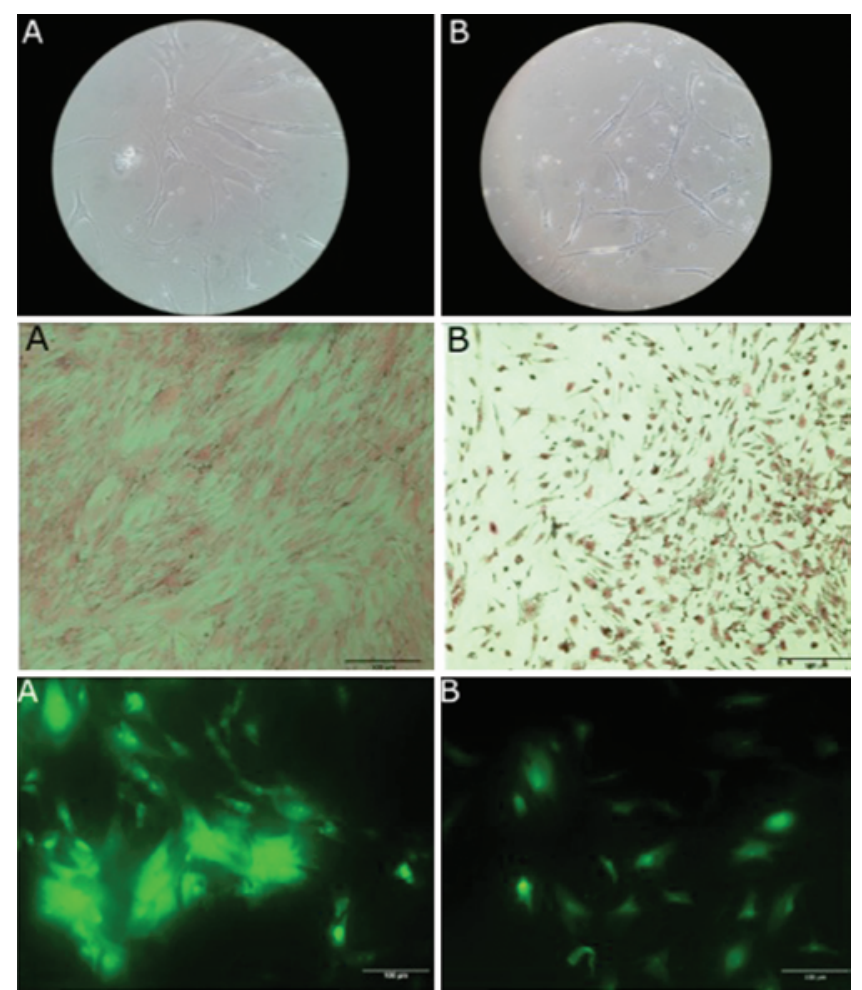

FIG. 5. Structural effects of $400 \mu \mathrm{g} / \mathrm{ml}$ of LV. Upper row: As observed using the inverted microscope, 3 days of treatment with $400 \mu \mathrm{g} / \mathrm{ml}$ of LV induced loss of pseudopodia formation and altered the normal shape of the cytoplasm. $A=$ control, $B=$ treated. Original magnification $\times 4$. Center row: The normal fusiform pattern was disrupted. $A=$ control, $B=$ untreated. $H \& E$, original magnification $\times 10$. Lower row: $A$ decreased number of viable (green) cells remained attached to the plate. $\mathrm{A}=$ control, $\mathrm{B}=$ untreated.

not at multiple time points. By assessing the cell count on numerous time points, our data show that dural fibroblast cells can overcome the detrimental effect of LV at a lower dose.

In vitro experiments do not take into consideration a number of variables present in a living organism. In this case, differences between our model and the actual environment of a healing wound include blood supply and a drain that may somewhat reduce the clinical concentration of LV. Also, the vancomycin powder and the dura can be (depending on the case) separated by a muscle layer, muscular fascia, and grafts commonly placed over the dura.

One of the difficulties that arises in studying the efficacy of LV is to determine the concentration of the drug to which the tissues are exposed. Depending on institutional preferences, the doses applied to the surgical bed can vary between 0.5 and $2 \mathrm{~g}$. An estimate of the concentration of LV can be obtained by sampling the drains after surgery, as shown by Sweet et al. ${ }^{18}$ They attempted to determine this concentration by analyzing the drain output. They found a mean concentration of $1457 \mu \mathrm{g} / \mathrm{ml}(95 \%$ CI $263-$ $2938 \mu \mathrm{g} / \mathrm{ml}$ ) on the same day of surgery and $128 \mu \mathrm{g} / \mathrm{ml}$ (95\% CI 37-311 $\mu \mathrm{g} / \mathrm{ml}) 5$ days after surgery. Because LV is applied as a precipitate, the quantity dissolved in the liquid drainage may not accurately represent the drug levels present in the tissue. The exact concentration of LV within the surgical wound may actually be quite higher than the concentration found within the surgical drain output.

The LV concentrations used in this study, representing the range that has been studied by prior investigators, severely negatively impacted the normal growing capacity of human dural fibroblasts. This inhibition of dural fibroblast proliferation might very well translate into a delay in the dural healing process after surgical closure of the dura. These LV dosages have also not been sufficiently correlated with the intended bactericidal effects in the clinical setting of spine surgery.

Future experiments will determine the effect of LV on dural healing in in vivo models, specifically evaluating the incidence of CSF leakage after durotomy repair with vancomycin powder application as well as its efficacy to prevent SSI. The goal for future studies will be to determine the specific dose of LV that is most effective in preventing SSI and at the same time does not impair normal tissue healing.

\section{Conclusions}

When vancomycin powder is applied locally, dural cells are exposed to a concentration several times greater than when delivered systemically. In this in vitro model, LV induced dural cell death, inhibited growth, and altered cellular morphology in a concentration-dependent fashion. Defining a safe LV concentration that is both bactericidal and also does not inhibit normal dural healing is necessary.

\section{References}

1. Bakhsheshian J, Dahdaleh NS, Lam SK, Savage JW, Smith ZA: The use of vancomycin powder in modern spine surgery: systematic review and meta-analysis of the clinical evidence. World Neurosurg 83:816-823, 2015

2. Buehlmann M, Frei R, Fenner L, Dangel M, Fluckiger U, Widmer AF: Highly effective regimen for decolonization of methicillin-resistant Staphylococcus aureus carriers. Infect Control Hosp Epidemiol 29:510-516, 2008

3. Cheadle WG: Risk factors for surgical site infection. Surg Infect (Larchmt) 7 (Suppl 1):S7-S11, 2006

4. Eder C, Schenk S, Trifinopoulos J, Külekci B, Kienzl M, Schildböck S, et al: Does intrawound application of vancomycin influence bone healing in spinal surgery? Eur Spine J 25:1021-1028, 2016

5. Evans RP: Surgical site infection prevention and control: an emerging paradigm. J Bone Joint Surg Am 91 (Suppl 6):2-9, 2009

6. Gans I, Dormans JP, Spiegel DA, Flynn JM, Sankar WN, Campbell RM, et al: Adjunctive vancomycin powder in pediatric spine surgery is safe. Spine (Phila Pa 1976) 38:17031707,2013

7. Goldschmidt E, Hem S, Ajler P, Ielpi M, Loresi M, Giunta $\mathrm{D}$, et al: A new model for dura mater healing: human dural fibroblast culture. Neurol Res 35:300-307, 2013

8. Goldschmidt E, Ielpi M, Loresi M, D'adamo M, Giunta D, Carrizo A, et al: Assessing the role of selected growth factors and cytostatic agents in an in vitro model of human dura mater healing. Neurol Res 36:1040-1046, 2014

9. Guerin P, El Fegoun AB, Obeid I, Gille O, Lelong L, Luc S, et al: Incidental durotomy during spine surgery: incidence, management and complications. A retrospective review. Injury 43:397-401, 2012 
10. Kalmeijer MD, Coertjens H, van Nieuwland-Bollen PM, Bogaers-Hofman D, de Baere GAJ, Stuurman A, et al: Surgical site infections in orthopedic surgery: the effect of mupirocin nasal ointment in a double-blind, randomized, placebo-controlled study. Clin Infect Dis 35:353-358, 2002

11. Kanayama M, Hashimoto T, Shigenobu K, Oha F, Togawa D: Effective prevention of surgical site infection using a Centers for Disease Control and Prevention guideline-based antimicrobial prophylaxis in lumbar spine surgery. J Neurosurg Spine 6:327-329, 2007

12. Khan NR, Thompson CJ, DeCuypere M, Angotti JM, Kalobwe E, Muhlbauer MS, et al: A meta-analysis of spinal surgical site infection and vancomycin powder. J Neurosurg Spine 21:974-983, 2014

13. Klekamp J, Spengler DM, McNamara MJ, Haas DW: Risk factors associated with methicillin-resistant staphylococcal wound infection after spinal surgery. J Spinal Disord 12:187-191, 1999

14. McMahon P, Dididze M, Levi AD: Incidental durotomy after spinal surgery: a prospective study in an academic institution. J Neurosurg Spine 17:30-36, 2012

15. Papavero L, Engler N, Kothe R: Incidental durotomy in spine surgery: first aid in ten steps. Eur Spine J 24:2077-2084, 2015

16. Rathbone CR, Cross JD, Brown KV, Murray CK, Wenke JC: Effect of various concentrations of antibiotics on osteogenic cell viability and activity. J Orthop Res 29:1070-1074, 2011

17. Smith JS, Shaffrey CI, Sansur CA, Berven SH, Fu KMG, Broadstone PA, et al: Rates of infection after spine surgery based on 108,419 procedures: a report from the Scoliosis Research Society Morbidity and Mortality Committee. Spine (Phila Pa 1976) 36:556-563, 2011

18. Sweet FA, Roh M, Sliva C: Intrawound application of vancomycin for prophylaxis in instrumented thoracolumbar fusions: efficacy, drug levels, and patient outcomes. Spine (Phila Pa 1976) 36:2084-2088, 2011

19. Theologis AA, Demirkiran G, Callahan M, Pekmezci M, Ames C, Deviren V: Local intra-wound vancomycin powder decreases the risk of surgical site infections in complex adult deformity reconstruction: a cost analysis. Spine (Phila Pa 1976) 39:1875-1880, 2014

20. Tubaki VR, Rajasekaran S, Shetty AP: Effects of using intravenous antibiotic only versus local intrawound vancomycin antibiotic powder application in addition to intravenous antibiotics on postoperative infection in spine surgery in 907 patients. Spine (Phila Pa 1976) 38:2149-2155, 2013

21. Xiong L, Pan Q, Jin G, Xu Y, Hirche C: Topical intrawound application of vancomycin powder in addition to intravenous administration of antibiotics: A meta-analysis on the deep infection after spinal surgeries. Orthop Traumatol Surg Res 100:785-789, 2014

\section{Disclosures}

The authors report no conflict of interest concerning the materials or methods used in this study or the findings specified in this paper.

\section{Author Contributions}

Conception and design: Gerszten, Goldschmidt, Rasmussen, Luzzi, Merlotti, Proni, Loresi. Acquisition of data: Goldschmidt, Rasmussen, Luzzi, Merlotti, Proni, Loresi. Analysis and interpretation of data: Goldschmidt, Rasmussen, Luzzi, Merlotti, Proni, Loresi. Drafting the article: Gerszten, Goldschmidt, Chabot, Gandhoke. Critically revising the article: Gerszten, Goldschmidt, Chabot, Gandhoke, Hamilton, Okonkwo, Kanter. Reviewed submitted version of manuscript: Gerszten, Goldschmidt, Chabot, Gandhoke, Hamilton, Okonkwo, Kanter. Statistical analysis: Goldschmidt. Administrative/technical/material support: Goldschmidt. Study supervision: Gerszten, Goldschmidt.

\section{Correspondence}

Peter C. Gerszten, Department of Neurological Surgery, Presbyterian University Hospital, Ste. B-400, 200 Lothrop St., Pittsburgh, PA 15213. email: gersztenpc@upmc.edu. 